\title{
REFLECTIONS A rural perspective: Four stories
}

\author{
Jenny Nash, Alwyn Rapatsa, Steve Reid, Ben Gaunt
}

These brief reflections from 4 University of Cape Town (UCT) medical graduates who chose to make their careers in rural practice are written in narrative style to try to capture something of the lived experience of working in rural areas. Although still the career choice of a minority of UCT graduates, those who have chosen to practise in rural areas have found a solid base of competence and confidence in their clinical skills, that has enabled them to tackle challenges in areas beyond anything that they or their teachers might have anticipated.

S Afr Med J 2012;102(6):433-434.
A baby cried. There was a collective sigh of relief from the surrounding faces, seen by the flickering light of a candle. The rest of the caesarean section proceeded uneventfully, now by the light of a torch. A torch often arrived just too late to herald in the arrival of a new baby. The anaesthetic machine checklist in a rural hospital should also include a torch with working batteries, candle and matches! After working for 10 years at a rural district hospital, these types of caesarean section still cause me tachycardia! However, the art of appearing calm slowly developed, thanks to the example set by a senior doctor, who never appeared flustered and was always ready to help in any crisis.

I had arrived at Mseleni Hospital immediately upon finishing my internship at Edendale Hospital in Pietermaritzburg. The nurturing environment provided by the 3 other doctors, the nursing staff and community members enabled my ongoing learning of medical skills, but also learning about people, and accountability to the community in which I was working. Thankfully, the dramas in theatre were not an everyday occurrence. Instead, more time was spent in the outpatient department and at the outlying clinics, interacting with patients and family members. Initially, this was as unfamiliar as theatre! Medical knowledge was refined and new skills were learned. Other skills, such as team work, conflict resolution, and cultural sensitivity, were cultivated. To work effectively within a small team, these 'soft skills' were found to be equally important as the clinical skills. Wise mentorship had enabled my medical training to blossom. I had learnt to think on my feet, to remain calm in crises, to realise the importance of communicating in a person's mother tongue, and to regard every human life I encountered with dignity and respect. It felt as if university was just the beginning of learning ...

\section{Jenny Nash}

After graduating MB ChB from the University of Cape Town (UCT) in 2002 , I had the privilege of experiencing the practice of clinical

Jenny Nash worked at Mseleni Hospital, KwaZulu-Natal from 1998 to 2007. Alwyn Rapatsa has worked at Ukwanda Centre for Rural Health, Worcester, from 2010. Steve Reid is the Director of Primary Health Care at the University of Cape Town and worked at Bethesda Hospital, Ubombo, KwaZulu-Natal from 1986 to 1995. Ben Gaunt has been working at Zithulele Hospital, Eastern Cape since 2005. medicine in different rural contexts within South Africa. I am grateful to have done my internship at Dihlabeng Hospital in Bethlehem as my experience there, coupled with the good knowledge base of medicine that I received from UCT, helped me to prepare for a career in family practice. After this splendid internship in the beautiful eastern Free State, I completed my community service year in the Eastern Cape at the Mthatha Hospital Complex and Isilimela Hospital, Port St Johns. It was a great pleasure to be in this part of the country and experience rural primary healthcare. The people taught me to serve and to appreciate life. Nowhere have I seen people who are so patient and appreciative of whatever I was able to do for them. I met my wife, who is originally from Port St Johns, during the 5-year period I worked in the Eastern Cape.

During my stay in Port St Johns and Mthatha I enrolled for an MMed in Family Medicine with the University of Pretoria and an MSc in Primary Health Care with University College, London, both by distance education. I was given a post that allowed me to rotate through specialist departments in order to fulfil the requirements of the MMed (Fam Med) training programme.

From February 2010 I have been working at the Ukwanda Centre for Rural Health (CRH) at Worcester Hospital, which is affiliated to Stellenbosch University's Division of Family Medicine and Primary Care, as a family physician. I joined Ukwanda at a time when a rural clinical school (RCS) was being developed, becoming involved in the training of under- and postgraduate students in family medicine. Notably, a number of undergraduates from Stellenbosch University currently spend their final year of training at the RCS.

In 1999 a UCT physician inspired me to appreciate primary healthcare from the point of view of clinical medicine. Professor Charles Swanepoel delivered a lecture entitled 'The kidney in primary healthcare' to my third-year medical class as part of the clinical methods course, and spoke passionately about primary healthcare and nephrology. It was as a result of these and other formative experiences at medical school, and my subsequent experience of good clinical medical practice in Bethlehem, that I decided to specialise in family medicine.

My hope is that those who currently work and teach at UCT's Faculty of Health Sciences, will continue to strive for excellence as their exemplary predecessors did, so that future generations of graduates will always have something positive to share about UCT's doctors.

\section{Alwyn Rapatsa}

It was a short distance, no more than 50 yards or so, between the front door of our house and the entrance to the outpatients and casualty 
department. But, it was a huge distance psychologically between home and work, between family and the distress of sick patients. In early years it was unpaved, a dirt road that turned to sticky mud in the summer storms, through which we had to pick our way, step by step, through each one of those 50 yards. It was also part of the main entrance to the hospital, so it was a place of greetings and roadside conversations in Zulu ... a familiar, shared space.

We traversed this path up and down, there and back, countless times over the 10 years we worked at that rural hospital. It led us again and again, back to a place of encounter, of learning, of coping with our inadequacies in the face of illness and distress brought about by factors far beyond our control. We mostly walked it, usually blithely, often expectantly, sometimes reluctantly, and occasionally grumpily, especially when there was yet another drunk patient who had interrupted sleep seeking treatment of his wounds from another overindulgence. On that dusty road I felt I sometimes walked like John Wayne, the only defence between me and the unpredictable drama of the casualty unit being a ballpoint pen in my left pocket with which to write prescriptions and orders that I hoped the nurses would carry out. We sometimes walked it in apprehension and fear, having been told over the phone what the problem was, and not knowing what to do. Quite often we ran, called by the desperate pleas of a midwife trying to resuscitate a newborn, or cope with an obstetric calamity beyond her abilities.

In the middle of the night from the deepest sleep, we might be roused by telephone to come as quickly as possible. There was that moment of anxiety when the phone first rang, worse in the first few years - a fear of the unknown, the possibility of being faced with a situation beyond our capability, mixed with some measure of intrigue. And, where a few minutes before, I might not have been particularly enthusiastic to do any further that evening, once the call came, there was no hesitation, no dilemma or question. My sleepy reluctance was swept aside by the reality of the patient's distress. On the path between my bed and the outpatients department, I transformed, I changed, from a sleepy companion into the role of the problem-solver, enticed by the possibilities and gripped by the energy of not knowing exactly what awaited me.

That path taught us many things. Back and forth we trudged, again and again, each time learning something new, sometimes just a nuance, or a variation on a well-rehearsed theme. Other times gave us some extraordinary first and only experiences that stick in memory. For example, the chap with the mamba bite who took nine ampoules of antivenom before he sat up suddenly and pulled the tube out of his throat. Or the time I was called in the middle of a stormy night to attempt to resuscitate six members of the same family who had been struck by lightning while sleeping in the same hut, and had died. Or the policeman who had been shot at point-blank range in the throat, and was in the process of exsanguinating until I blindly stuck an endotracheal tube down his throat and inflated the cuff. Most often, though, an after-hours summons was for an emergency caesarean section, or to administer the anaesthetic for a colleague who was operating. In the dead of the night, with just 4 or 5 of us sorting out the problem, only we knew the true story: how close the patient had come to dying, the level of our desperation at the critical moment of the operation, and how the situation had eventually played itself out. It was almost conspiratorial, as if we were on a lifeboat with the patient in the middle of a sea of complacency, as everyone else in the world slept the sleep of the good.

The walk back home was usually slower than the walk to the hospital ... ambling home after a long afternoon in the outpatients department, or stumbling home in the middle of the night after a session in the operating theatre, pondering the operation that had just been performed and knowing that I wouldn't easily get back to sleep. Stepping through the front door, trying to make the transition back to being a father and partner, while the drama of the patient's situation replayed itself in my mind; drawing up the defences, shaking off the emotions of the desperate and the dying, I let out a breath and resumed my family role, trying to be normal.

(Note: this piece was first published in South African Family Practice 2010;52(6):535)

\section{Steve Reid}

One of my favourite memories of third-year pathology is of Maureen Duffield asking our group how we would diagnose or treat something when we were 'under the bongo-bongo tree in Putsonderwater'? She was speaking my language.

A sense that our calling was to rural medicine grew into a passion for the field, that was stoked watching a video called 'Medicine in Maputoland' in a fourth-year primary healthcare rotation. By the time we graduated my class had voted me 'most likely to end in the sticks voluntarily' and Taryn (we married at varsity) had a similar reputation in her class.

Today, as we look out at the rolling hills from our home in the deeply rural Wild Coast, we marvel at how many people have helped shape and fulfil the dream of providing high-quality care to our rural community. A remarkable number have been UCT graduates. Too many to mention by name, they range from school and varsity friends who have worked alongside us here, to others who have specialised and offer advice on outreach or by phone. Many others, from UCT and elsewhere, have been mentors along the way.

UCT instilled in us an ethos of doing things properly. We were taught to think - a skill that has come in useful as 'problem-solvers in chief' even if the curriculum didn't teach us about fixing sewage pumps or human resource systems. We didn't learn enough about the allied health professions either, but the reality of a small rural hospital has helped forge a multidisciplinary team that provides genuine all-round care to our patients.

Success is hard to measure when you're surrounded by need, in a world that emphasises career aspirations over making a difference. We are thrilled by our declining perinatal and paediatric mortality rates, and equally by the specialised wheelchairs our rehabilitation team issue. But our biggest success is learning daily to look past the pathology to the person we're helping.

Many challenges still await us. With hospital services on an even keel, we are pursuing an ever more ambitious programme of outreach to our clinics and dream of making primary healthcare and the benefits of the National Health Insurance scheme a tangible reality for our community.

Much has changed in 6 years: access to laboratory tests is now Monday to Friday, instead of once weekly; our X-rays are digital; our mobile internet is HSPA+. But, the bongo-bongo trees still grow in great numbers on the hills. Helping the communities that meet under them is a challenge that will yet occupy many generations of health professionals.

\section{Ben Gaunt}

